\title{
Endoscopic ultrasound-guided pancreatic duct drainage: technical approaches to a challenging procedure
}

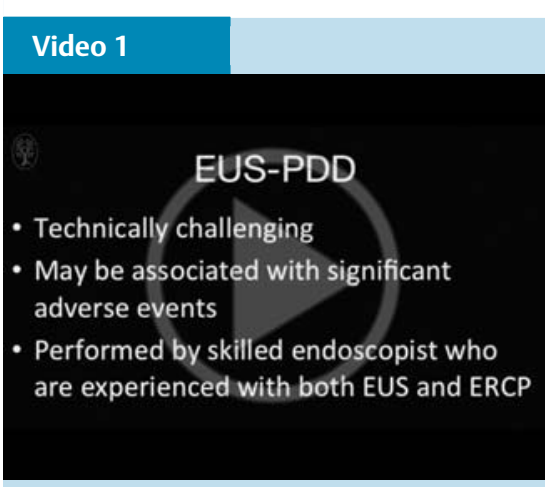

Three approaches to endoscopic ultrasoundguided pancreatic duct drainage.

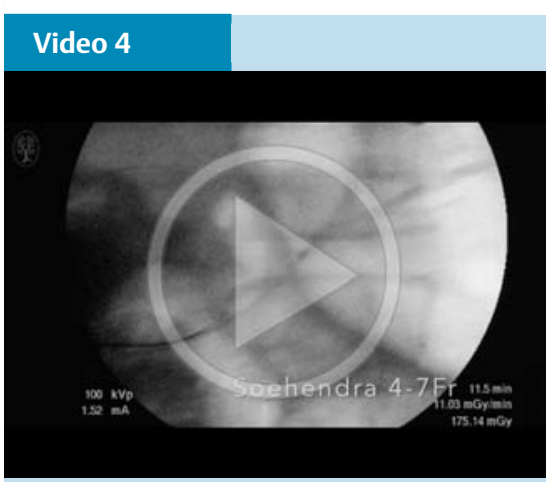

Anterograde drainage approach to endoscopic ultrasound-guided pancreatic duct drainage.

Endoscopic ultrasound-guided pancreatic duct drainage (EUS-PDD) is an effective treatment modality for pancreatic pathologies, including chronic pancreatitis, major or minor papilla inaccessible via endoscopic retrograde cholangiopancrea-

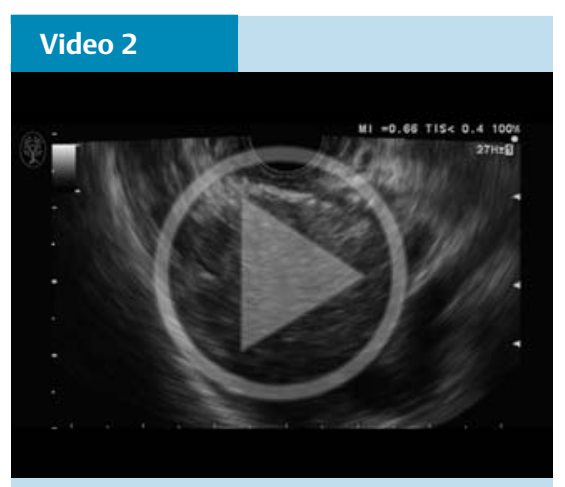

Transluminal pancreaticogastrostomy approach to endoscopic ultrasound-guided pancreatic duct drainage.

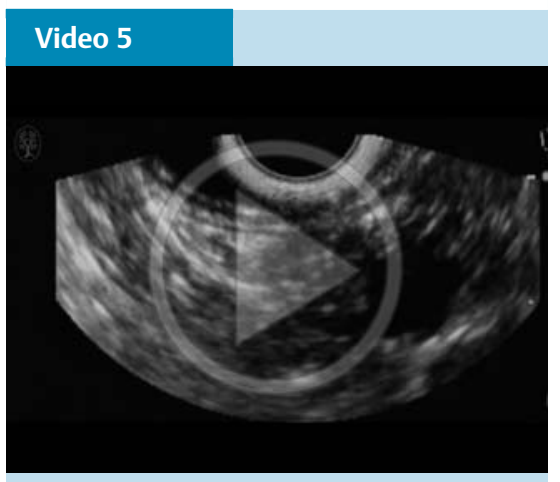

Rendezvous approach to endoscopic ultrasound-guided pancreatic duct drainage.

tography, and postsurgical pancreaticoenterostomy stricture [1,2]. Technically, however, EUS-PDD can be very difficult and is potentially associated with significant complications [3]. The following series of videos aims to improve the under-

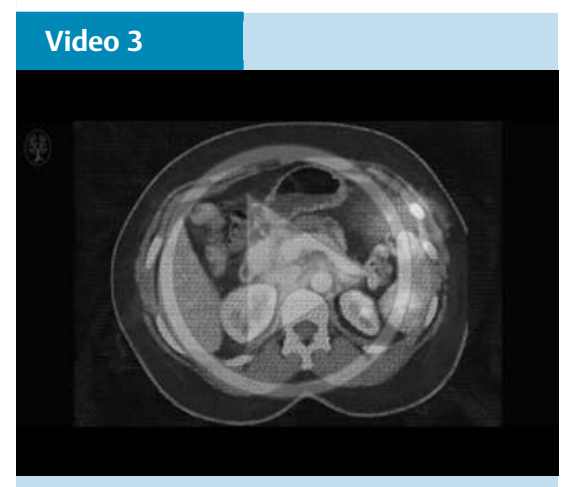

Transluminal pancreaticoduodenostomy approach to endoscopic ultrasound-guided pancreatic duct drainage.

standing and performance of EUS-PDD by describing the three approaches to this challenging procedure ( Video 1 ): the transluminal stenting, anterograde drainage, and rendezvous method. To our knowledge, this is the first published video series focused on the different methods and steps of this intricate procedure.

Case 1 describes a 55-year-old man with a pancreaticoenterostomy stricture following Whipple surgery. It showcases the transluminal approach, where a stent is placed upstream from thestrictureforming a pancreaticogastrostomy ( Fig. $1 \mathrm{a}-\mathrm{c}$, - Video 2). The patient's symptoms improved dramatically following the procedure.

Case 2 is another example of the transluminal approach; however, this time it demonstrates the creation of a pancreaticoduodenostomy with the insertion of
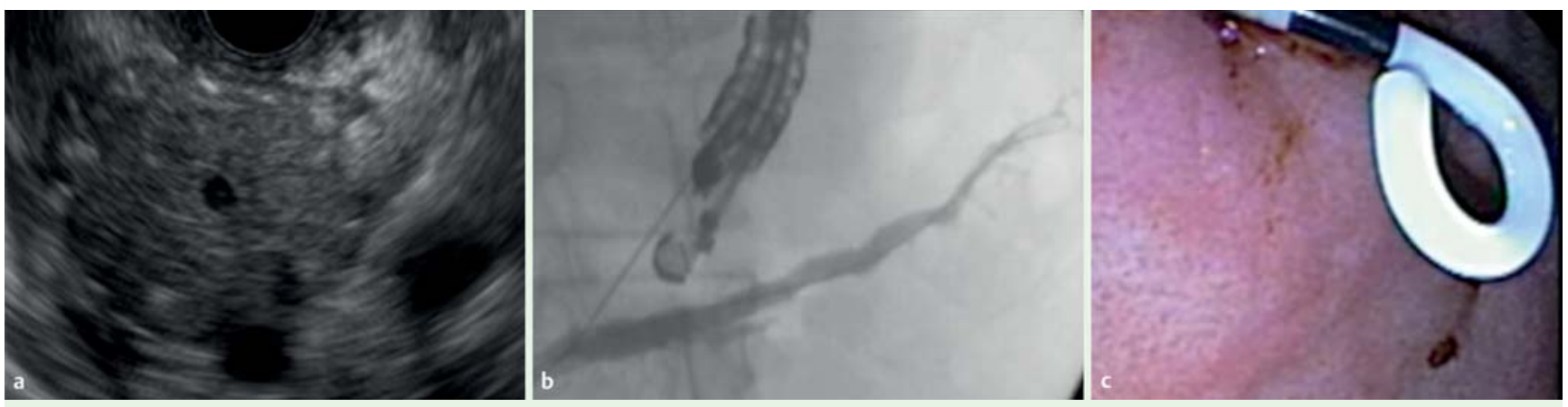

Fig. 1 Transluminal approach to endoscopic ultrasound-guided pancreatic duct drainage. a The dilated pancreatic duct measured $4 \mathrm{~mm}$ at the pancreatic body. b A 19-gauge needle successfully punctured the main pancreatic duct, and a guidewire was subsequently inserted. c Following tract dilation, a plastic pigtail pancreatic stent was inserted, forming a pancreaticogastrostomy. 
a plastic stent in a patient with pancreatic divisum and chronic pancreatitis (- Video 3).

Case 3 shows anterograde drainage, where a stent is inserted downstream through a pancreaticoenterostomy stricture in order to manage a patient with recurrent pancreatitis following pancreaticoduodenectomy ( Video 4 ). The patient responded well to the treatment with no recurrence of pancreatitis at the last follow-up. Case 4 shows the rendezvous technique where EUS-assisted pancreatic access is performed in order to guide subsequent endoscopic retrograde pancreatography in a patient with recurrent alcohol pancreatitis ( $\bullet$ Video 5 ). The patient was free from pain at the 1-year post-procedure follow-up appointment.

EUS-PDD is an important minimally invasive modality in the management of several pancreatic pathologies. We have described the different approaches and steps needed to perform this intricate procedure in the hope of improving the understanding of the technique and the subtle nuances involved.
Endoscopy_UCTN_Code_TTT_1AS_2AD

Competing interests: Dr. Khashab is a consultant for Boston Scientific

\section{Yen-I Chen ${ }^{1}$, Payal Saxena ${ }^{2}$, Saowanee Ngamruengphong ${ }^{1}$, Yamile Haito-Chavez ${ }^{1}$, Majidah Bukhari ${ }^{1}$, Everson Artifon ${ }^{3}$, Mouen A. Khashab ${ }^{1}$}

${ }^{1}$ Department of Medicine and Division of Gastroenterology and Hepatology, The Johns Hopkins Medical Institutions, Baltimore, Maryland, United States

2 Department of Medicine and Division of Gastoenterology, Royal Prince Alfred Hospital, Camperdown, New South Wales, Australia

${ }^{3}$ Gl Endoscopy, Ana Costa Hospital, Santos, Brazil

\section{References}

1 Fujii-Lau LL, Levy MJ. Endoscopic ultrasound-guided pancreatic duct drainage. J Hepatobiliary Pancreat Sci 2015; 22: 51 - 57

2 Itoi T, Kasuya K, Sofuni A et al. Endoscopic ultrasonography-guided pancreatic duct access: techniques and literature review of pancreatography, transmural drainage and rendezvous techniques. Dig Endosc 2013; 25: $241-252$

3 Fujii LL, Topazian MD, Abu Dayyeh BK et al. EUS-guided pancreatic duct intervention: outcomes of a single tertiary-care referral center experience. Gastrointest Endosc 2013; 78: 854-864

Bibliography

DOI http://dx.doi.org/

10.1055/s-0042-107075

Endoscopy 2016; 48: E192-E193

(c) Georg Thieme Verlag KG

Stuttgart · New York

ISSN 0013-726X

Corresponding author

Mouen A. Khashab, MD

Division of Gastroenterology and Hepatology

Johns Hopkins Hospital

1800 Orleans Street, Suite 7125B

Baltimore, MD 21287

United States

Fax: +1-443-683-8335

mkhasha1@jhmi.edu 